\title{
Brain arteriovenous malformation with transdural blood supply: Current status (Review)
}

\author{
JIANMIN PIAO ${ }^{1}$, TIEFENG $\mathrm{JI}^{2}$, YUNBAO GUO ${ }^{1}$, KAN XU ${ }^{1}$ and JINLU YU $^{1}$ \\ Departments of ${ }^{1}$ Neurosurgery and ${ }^{2}$ Radiology, The First Hospital of Jilin University, Changchun, Jilin 130021, P.R. China
}

Received November 13, 2018; Accepted May 31, 2019

DOI: $10.3892 /$ etm.2019.7731

\begin{abstract}
Arterial blood supply to a brain arteriovenous malformation (BAVM) is mainly derived from the internal carotid artery (ICA) and vertebral basilar artery (VBA) system. However, in certain cases, arteries supplying the meninges may also contribute to the blood supply of the BAVM, resulting in the formation of a BAVM with transdural blood supply (TBS). To review the current status of BAVM with TBS, a literature search was performed in the PubMed database. Articles were screened for relevance and suitability of data. According to recent studies, the mechanisms by which TBS to a BAVM forms are mainly classified into the congenital and acquired type. BAVM with TBS is common in elderly patients and is characterized by intracranial hemorrhage, epilepsy, chronic headache and increased intracranial pressure. Digital subtraction angiography is the gold standard for diagnosing BAVM with TBS. Superselective angiography is also important. Treatments for BAVM with TBS include surgical resection, endovascular treatment (EVT), stereotactic radiosurgery and combined treatment. Surgical resection is difficult to perform. EVT has become the major therapy for treating BAVM with TBS due to its low procedural invasiveness. Combination of surgical resection and EVT may be a good option. In addition, stereotactic radiosurgery is frequently used as a complementary treatment to surgical and endovascular interventions. The prognosis of BAVM with TBS is not favorable, as the defect involves a complex arterial supply system.
\end{abstract}

\section{Contents}

1. Introduction

2. Incidence

3. Pathogenesis

Correspondence to: Dr Jinlu Yu, Department of Neurosurgery, The First Hospital of Jilin University, 71 Xinmin Avenue, Changchun, Jilin 130021, P.R. China

E-mail: jinluyu@hotmail.com

Key words: brain arteriovenous malformation, transdural blood supply, review
4. Angioarchitecture
5. Clinical manifestations
6. Imaging examinations
7. Treatment
8. Prognosis
9. Conclusions
10. Typical case of BAVM with TBS

\section{Introduction}

Brain arteriovenous malformation (BAVM) refers to a cluster of direct connections between arteries and draining veins without an intervening capillary bed. AVMs have the following major components: One or more feeding arteries, a nidus that forms the site of the arteriovenous shunt and draining venous structures $(1,2)$. The arteries that supply blood to a BAVM mainly arise from the internal carotid artery (ICA) and vertebral basilar artery (VBA) systems $(3,4)$.

However, when the BAVM is adjacent to cerebral convexities or intracranial dural structures, the arteries that supply the BAVM may also originate or even be wholly derived from the arteries supplying the meninges. These latter structures are called BAVM with transdural blood supply (TBS) $(5,6)$. The TBS of BAVM may be from the external carotid artery (ECA) or the meningeal branches of the ICA and the VBA system (7).

To date, a relatively limited number of studies have reported on BAVM with TBS; thus, the current knowledge is insufficient. Furthermore, no comprehensive review has been previously published. Hence, for the present article, a literature search was performed using the PubMed database to review BAVM with TBS.

\section{Incidence}

BAVM with TBS has long been in the spotlight of research, while incidences of BAVM with TBS are significantly different among published studies. For instance, according to the study by Willinsky et al (8), the incidence was $29 \%$. Newton and Cronqvist (9) reported an incidence of $27 \%$. However, Miyachi et al (10) reported an incidence of $65 \%$.

Compared with that reported by Miyachi et al (10), the studies by Willinsky et al (8) and Newton and Cronqvist (9) reported a lower incidence of TBS, as they included whole-brain BAVM in their studies. The study by Miyachi et al (10) mainly 
focused on superficial-area BAVM, and as BAVM with TBS usually occurs in subpial areas and the cortex, they estimated a relatively higher incidence of BAVM with TBS than the other studies.

Among whole-brain studies of BAVM, the study by Bervini et al (7) appears to have assessed the incidence of TBS in the most suitable manner. This study included 769 cases of BAVM; of these, 51 cases had a TBS, resulting in an incidence of $6.6 \%$ (7). The incidence of TBS in other studies was higher, perhaps due to confusion regarding the classification of BAVM with TBS during the early years of research or differences in angiographic techniques, as well as the location of the BAVMs included (11).

\section{Pathogenesis}

The mechanisms by which TBS forms in a BAVM with TBS are mainly divided into the congenital and acquired type.

Congenital factors. The congenital formation theory of TBS has demonstrated that TBS developed upon generation of the BAVM, according to which BAVM with TBS form during embryonic development of the cerebral circulation (7). Miyachi et al (10) indicated that in early embryos, the epidural blood supply originates from pial-dural anastomotic channels. Hence, during the embryonic development of a BAVM, the BAVM may acquire a TBS.

Acquired factors. In recent years, TBS of BAVM has been more frequently regarded as acquired $(5,12-14)$. This may occur in two situations: i) The formation of the BAVM is congenital, and only the formation of TBS is acquired; ii) the formation of the BAVM and the TBS is acquired (15). Acquired mechanisms mainly attribute to sinus thrombosis and hypertension, including trauma, radiation, infection, surgery and transarterial embolization $(6,15-18)$. When the above factors induce sinus thrombosis or thrombosis, the endogenous dysplastic dural vessels in the sinus further develop and directly induce an artery-to-sinus communication, thus forming a BAVM with TBS $(6,13,17,19-21)$.

In addition, the inflammation caused by the use of glue or the Onyx Liquid Embolic System (Medtronic Plc) during embolization may stimulate the formation of a BAVM in a superficial area, resulting in the formation of a TBS (5). Subsequent to the establishment of BAVM, high wall shear stress can cause angiogenesis and arteriogenesis to recruit the TBS that directly supplies the BAVM (7).

\section{Angioarchitecture}

The characteristics of the angioarchitecture of BAVM with TBS include its size, location, arterial blood supply artery (including a TBS), nidus structure and drainage vein (22).

Location. The nidus of a BAVM with TBS is usually located in a superficial area, including the subpial area or the cortex, but may occasionally appear around the tentorium, skull base or posterior fossa (22). Koo et al (11) reported that BAVM with TBS was most commonly observed in the temporal lobe (34.4\%), followed by the occipital lobe (28.1\%), parietal lobe
(18.8\%) and frontal lobe (12.5\%). Soderman et al (6) also indicated that BAVM with TBS most commonly occurs in the temporal lobe, followed by the parietal lobe and frontal lobe. The reason why the temporal lobe is a relatively common location may be due to this site being the major region supplied by blood from the middle meningeal artery (MMA) and occipital artery $(6,11)$.

Feeding artery and draining vein. The major supplying arteries of a BAVM with TBS include the non-meningeal branches of the ICA and VBA system; the meningeal branches of the ECA, ICA and VBA systems may also be involved in BAVM that acquire a TBS $(23,24)$. In rare cases, a BAVM will exclusively receive its blood from a TBS $(7,25)$. Of all types of TBS, those from the MMA and occipital artery are the most common, accounting for $86 \%$ of all types (23). Due to the presence of a TBS for the BAVM, the venous drainage from the BAVM may be similar to that of a dural arteriovenous fistula, which may have cortical venous retrograde drainage, and the drainage veins of a BAVM may be tortuous or variceal and exhibit aneurysmal dilation $(22,26)$.

Nidus. BAVMs are divided into large vs. small and compact vs. diffuse types according to the size and compactness of the nidus, respectively (27-29). In a BAVM with TBS, a larger nidus is associated with a higher probability of a TBS. The reasons for this association may be that larger BAVMs are more frequently close to the dura mater and associated with a more complex source of arterial blood supply $(6,7,10)$.

For instance, Koo et al (11) indicated that the probability of a TBS occurring in a BAVM with an AVM volume in the nidus of $>10 \mathrm{~cm}^{3}$ was higher than that for a BAVM with a nidus of 4-10 $\mathrm{cm}^{3}$. In addition, it is more likely for a TBS to appear in a diffuse-type BAVM (30). Miyachi et al (10) and Koo et al (11) reported that diffuse-type BAVMs were associated with a significantly higher incidence of TBS.

\section{Clinical manifestations}

The clinical manifestations of BAVM with TBS are similar but not identical to those of BAVM without TBS. The blood-supplying artery of a BAVM with TBS involves the dura; thus, the clinical manifestations of the BAVM share the characteristics of the dura (31). However, the major clinical manifestations are associated with the size and location of the BAVM.

General characteristics. BAVM with TBS is mostly observed in elderly patients, and its incidence increases with age $(6,7,10)$. Dahl et al (32) reported that the maximum age at onset of BAVM with TBS is 50-60 years. Bervini et al (7) reported that the average age of patients with BAVM with TBS was 43 years, which is obviously higher than that of BAVM patients without TBS (with an average age of 37 years), perhaps due to a BAVM taking a certain time to acquire a TBS.

Whether the incidence of BAVM with TBS is associated with gender has not been clearly determined by previous studies. It has been noted that BAVM with TBS occurring in the anterior cranial fossa is more common in males than in females, an effect that may be linked to factors including 
trauma (33). By contrast, BAVM with TBS in other locations is more likely to occur in females (34).

Intracranial hemorrhage. The most important clinical manifestation of BAVM with TBS is intracranial hemorrhage, which is life-threatening in severe cases (35). For instance, nine of the 30 cases of BAVM with TBS reported by Jin et al (36) were caused by intracranial hemorrhage (incidence, 30.0\%). Intracranial hemorrhage may occur at the BAVM nidus or from aneurysmal dilated drained veins, with the latter being more common than the former, and is characterized by intracranial hematoma and subarachnoid hemorrhage (37).

Subdural hematoma is associated with bleeding of BAVM with TBS. As BAVM with TBS tend to be located at the surface of the brain, ruptures in the small blood supply arteries between the dura mater and cortex seep into the subdural region (38), with trauma being a likely cause. For instance, Kominato et al (39) reported on a female patient who died of acute subdural hematoma, and autopsy confirmed that the patient had a BAVM with TBS in the falx cerebri.

Epilepsy. Epilepsy is the major non-hemorrhage symptom of BAVM with TBS. Epilepsy occurs in affected patients due to the location of the BAVM nidus usually involving the cerebral cortex. Thus, the BAVM stimulates abnormal discharges in the pia mater and cortex, thereby causing epilepsy (40). Furthermore, vein pulsations, which are caused by vein hypertension and are increased by vein resistance, may occur and increase the incidence of epileptic seizures $(41,42)$.

Other symptoms. Regarding other clinical symptoms, BAVM with TBS is associated with chronic headache. For instance, Koo et al (11) determined that chronic headache occurred 3.7 times more frequently in patients with BAVM with TBS than in those with BAVM without TBS, suggesting that TBS itself is associated with chronic headache. Increased intracranial pressure is another common clinical manifestation of BAVM with TBS. The mechanism underlying this symptom may be an increase in pressure and the flow of arterialized meningeal sinuses $(43,44)$.

In addition, the hemodynamic factors associated with BAVM with TBS may also cause corresponding symptoms. For instance, the diversion of blood flow from the ophthalmic artery to the BAVM may cause amaurosis fugax (37). Other rare symptoms include cranial nerve palsy and trigeminal neuralgia, and these symptoms are considered to be caused by cranial nerve compression by enlarged and serpiginous draining veins $(45,46)$.

\section{Imaging examinations}

The clinical manifestations of BAVM with TBS are nonspecific. Therefore, imaging, including digital subtraction angiography (DSA), computed tomography (CT) angiography and magnetic resonance angiography are the major methods used to diagnose BAVM with TBS. Among these, DSA is the gold standard for diagnosis (26). However, for BAVM with TBS, selective angiographies, including selective ECA and ICA angiogram, or superselective angiography, are important.
The characteristics of BAVM with TBS that may be clearly observed on selective and superselective angiography include the following: A nidus located close to the surface of the brain, blood-supplying arteries originating from both epidural and intracranial arteries, and venous drainage to the dural sinus and/or leptomeningeal vein $(24,47)$. Retrograde leptomeningeal venous drainage is frequently tortuous, variceal or frankly aneurysmal (5).

\section{Treatment}

The treatment plan for BAVM with TBS generally includes surgical resection, endovascular treatment (EVT), stereotactic radiosurgery and combined treatment $(22,48-51)$. The choice of treatment components is a multidisciplinary decision that requires an evaluation of the anatomical location of the BAVM, Spetzler-Martin classification and hemodynamics, and the decision should be made by local experts and the patient (52).

Surgical resection. Complete surgical resection is the most effective treatment for BAVM with TBS, but as it involves numerous and complex arrangements of feeding arteries and drainage veins, the operation is difficult to perform. TBS in particular increases the risk of the operation (53). Intra-operatively separating the dura mater from the BAVM surface may tear the corresponding dural blood supply arteries, causing catastrophic hemorrhage. To prevent this from occurring, it is suggested that the dura and all of its blood-supplying arteries connected to the BAVM should be resected (54).

In cases of BAVM with TBS caused by hemorrhaging of the expanded drainage vein, simple surgical interruption of the draining vein may be a successful treatment. However, to prevent rebleeding, the focal point and nidus should also be amputated $(55,56)$.

Endovascular treatment. At present, EVT is one of the methods used for treating BAVM with TBS. The advantage of EVT is its low procedural invasiveness and preservation of brain functionality (52). Performing EVT in BAVM with TBS mainly involves transarterial embolization, which is performed via either a dural blood supply approach or a pial blood supply approach (non-dural blood supply approach) (36).

Among these, the pial blood supply approach in EVT may effectively embolize the BAVM and prevent rebleeding (57). However, the dural blood supply approach is safer; furthermore, by reducing the blood flow of the brain surface, certain clinical symptoms may be improved, including epilepsy and headache from dural feeding pulsation, particularly in unruptured BAVM with TBS (36). During the dural blood supply approach, the use of a dual-lumen balloon catheter is helpful to inject the liquid embolic material into the BAVM to prevent reflux $(58,59)$.

Combination of surgical and endovascular approaches. During surgical resection of BAVM with TBS, the corresponding dural blood-supplying arteries should be controlled prior to performing the nidus resection to reduce the risk of intra-operative bleeding $(60,61)$. Thus, in earlier studies, it was a feasible choice to perform ECA ligation (53). The combination of surgical and endovascular methods for intracranial 

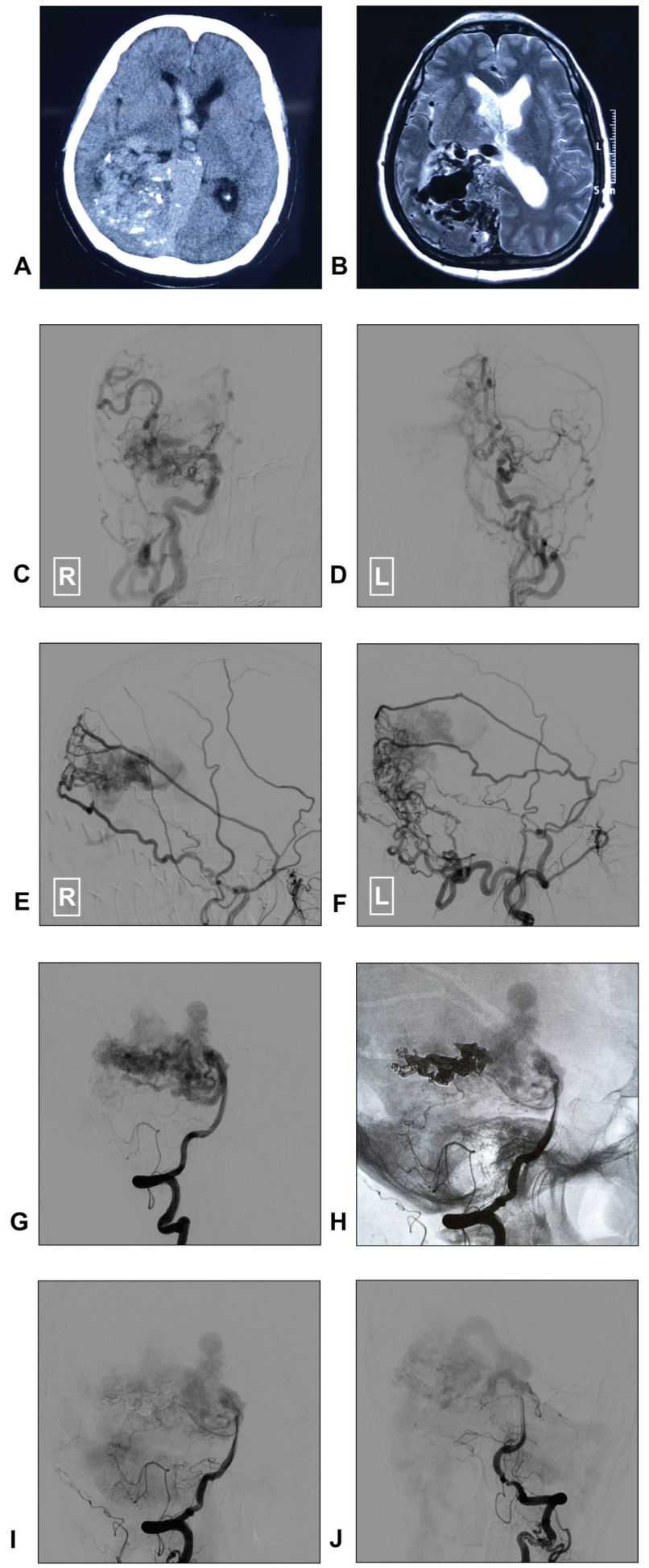

Figure 1. One typical case of BAVM with TBS. (A and B) Head CT and MRI displaying BAVM in the lateral ventricle triangle of the right occipital lobe and temporal lobe. Slightly high density was observed on CT, and MRI indicated voids in vessels. The BAVM was ruptured with bleeding into the right lateral ventricle and third ventricle. (C and D) Bilateral carotid artery angiography revealed that the bilateral internal carotid system was involved in the blood supply of the BAVM (E and F) Bilateral external carotid artery system angiography indicated that the middle cerebral artery and occipital artery were involved in the blood supply. (G) Vertebral basilar angiography demonstrated that the BAVM was mainly supplied by the posterior cerebral artery. (H-J) Onyx embolization via multiple branches of the posterior cerebral artery was performed to treat the BAVM, and target embolization was the major method utilized to treat the BAVM near the ventricle. CT, computed tomography; MRI, magnetic resonance imaging; BAVM, brain arteriovenous malformation; TBS, transdural blood supply. neurovascular diseases in a hybrid operating room is a novel and promising trend $(62,63)$, and in modern case series, numerous TBS were selectively embolized as a surgical adjunct to make surgical resection safer.

Stereotactic radiosurgery. Stereotactic radiosurgery is generally not the first choice for BAVM with TBS and is frequently used as a complementary treatment after surgical treatment and intravascular intervention. The aim of stereotactic radiosurgery in those cases is to further and more completely remove the nidus (64). However, a previous study described the successful treatment of BAVM with TBS by stereotactic radiosurgery alone (51). In 1993, Chandler and Friedman (49) reported on one case of BAVM with TBS located in the anterior cranial fossa that was treated with 3,000 cGy to the $80 \%$ isodose line of an 18 -mm collimator, and angiography performed after 3 years indicated that the BAVM had disappeared.

\section{Prognosis}

As BAVM with TBS is not frequently reported, the prognosis of BAVM with TBS is uncertain. It is now agreed that, due to BAVM with TBS involving a complex supply of arteries, the therapeutic outcomes are generally poor. Shima et al (56) reported that the surgical cure rate for BAVM with TBS was low, while its morbidity and mortality were high. If resection is not complete, the BAVM nidus may expand or cause disastrous intracerebral hemorrhage (56).

Soderman et al (6) reported on EVT performed on 54 cases of BAVM with TBS, $22 \%$ of whom required retreatment by EVT after 3 years of follow-up, indicating that the imaging-based cure rate was not ideal. However, with the continuous enhancement of the understanding BAVM with TBS, treatment outcomes are also gradually improving (65).

\section{Conclusions}

BAVM with TBS are different from those observed in common BAVM. The mechanisms by which TBS may form in a BAVM are mainly divided into the congenital and acquired type, the acquired factor may be popular $(5,12-14)$. BAVM with TBS is common in elderly patients. DSA is the gold standard for diagnosing BAVM with TBS. Superselective angiography is also important. Treatments for BAVM with TBS include surgical resection, EVT, stereotactic radiosurgery and combined treatment. Surgical resection is difficult to perform. EVT has become the major method for treating BAVM with TBS due to its low procedural invasiveness. Combination of surgical resection and EVT may be a good option. In addition, stereotactic radiosurgery is frequently used as a complementary treatment to surgical and endovascular interventions. The prognosis of BAVM with TBS is not optimistic.

\section{Typical case of BAVM with TBS}

The patient, a 65-year-old female, with no history of hypertension or diabetes mellitus was admitted the First Hospital of Jilin University (Changchun, China) in March 2018 due to presentation of a sudden headache and vomiting for $1 \mathrm{~h}$. After its onset, the patient was mentally lucid and had flexible limbs. 
Head CT and magnetic resonance imaging revealed a BAVM near the right temporal occipital lobe and corpus callosum, and right ventricular hemorrhage (Fig. 1A-B). DSA revealed a BAVM with TBS of the bilateral ECA and ICA systems (Fig. 1C-G). To treat the BAVM near the ventricle, Onyx embolization was performed via the posterior cerebral artery, and targeted embolization was performed to treat the BAVM near the hemorrhage point (Fig. $1 \mathrm{H}-\mathrm{J})$. The patient recovered well after surgery and exhibited no new neurological deficits (Fig. 1).

\section{Acknowledgements}

Not applicable.

\section{Funding}

No funding was received.

\section{Availability of data and materials}

All data generated or analyzed during this study are included in this published article.

\section{Authors' contributions}

JY and KX conceived and designed the study. TJ and YG acquired the data. JP drafted the manuscript. All of the authors have read and approved the final manuscript.

\section{Ethics approval and consent to participate}

This case study was approved by the Ethics Committee of the First Hospital of Jilin University (Changchun, China). The patient signed informed consent for use of clinical data and images.

\section{Patient consent for publication}

Written informed consent was obtained from the patient for the publication of data/information.

\section{Competing interests}

The authors declare that they have no competing interests.

\section{References}

1. Josephson CB, Rosenow F and Al-Shahi Salman R: Intracranial vascular malformations and epilepsy. Semin Neurol 35: 223-234, 2015.

2. Mouchtouris N, Jabbour PM, Starke RM, Hasan DM, Zanaty M, Theofanis T, Ding D, Tjoumakaris SI, Dumont AS, Ghobrial GM, et al: Biology of cerebral arteriovenous malformations with a focus on inflammation. J Cereb Blood Flow Metab 35: 167-175, 2015.

3. Sanborn MR, Park MS, McDougall CG and Albuquerque FC: Endovascular approaches to pial arteriovenous malformations. Neurosurg Clin N Am 25: 529-537, 2014.

4. Crowley RW, Ducruet AF, McDougall CG and Albuquerque FC: Endovascular advances for brain arteriovenous malformations. Neurosurgery 1 (Suppl 74): S74-S82, 2014.

5. Heros RC: Editorial. Transdural arterial recruitment to brain arteriovenous malformations. J Neurosurg 127: 47-50, 2017.
6. Soderman M, Rodesch G and Lasjaunias P: Transdural blood supply to cerebral arteriovenous malformations adjacent to the dura mater. AJNR Am J Neuroradiol 23: 1295-1300, 2002.

7. Bervini D, Morgan MK, Stoodley MA and Heller GZ: Transdural arterial recruitment to brain arteriovenous malformation: Clinical and management implications in a prospective cohort series. J Neurosurg 127: 51-58, 2017.

8. Willinsky R, Lasjaunias P, Terbrugge $\mathrm{K}$ and Pruvost P: Brain arteriovenous malformations: Analysis of the angio-architecture in relationship to hemorrhage (based on 152 patients explored and/or treated at the hopital de Bicetre between 1981 and 1986). J Neuroradiol 15: 225-237, 1988 (In English, French).

9. Newton TH and Cronqvist S: Involvement of dural arteries in intracranial arteriovenous malformations. Radiology 93: 1071-1078, 1969.

10. Miyachi S, Negoro M, Handa T and Sugita K: Contribution of meningeal arteries to cerebral arteriovenous malformations. Neuroradiology 35: 205-209, 1993.

11. Koo HW, Jo KI, Yeon JY, Kim KH, Jeon P, Kim JS, Hong SC, Shin HJ and Lee JI: Clinical features of superficially located brain arteriovenous malformations with transdural arterial communication. Cerebrovasc Dis 41: 204-210, 2016.

12. Chaudhary MY, Sachdev VP, Cho SH, Weitzner I Jr, Puljic S and Huang YP: Dural arteriovenous malformation of the major venous sinuses: An acquired lesion. AJNR Am J Neuroradiol 3: 13-19, 1982.

13. Russell EJ and Berenstein A: Meningeal collateralization to normal cerebral vessels associated with intracerebral arteriovenous malformations: Functional angiographic considerations. Radiology 139: 617-622, 1981.

14. Nabors MW, Azzam CJ, Albanna FJ, Gulya AJ, Davis DO and Kobrine AI: Delayed postoperative dural arteriovenous malformations. Report of two cases. J Neurosurg 66: 768-772, 1987.

15. Sturiale CL, Puca A, Sebastiani P, Gatto I, Albanese A, Di Rocco C, Maira G and Pola R: Single nucleotide polymorphisms associated with sporadic brain arteriovenous malformations: Where do we stand? Brain 136: 665-681, 2013.

16. Herman JM, Spetzler RF, Bederson JB, Kurbat JM and Zabramski JM: Genesis of a dural arteriovenous malformation in a rat model. J Neurosurg 83: 539-545, 1995.

17. Houser OW, Campbell JK, Campbell RJ and Sundt TM Jr: Arteriovenous malformation affecting the transverse dural venous sinus-an acquired lesion. Mayo Clin Proc 54: 651-661, 1979.

18. Jeffree RL and Stoodley MA: Postnatal development of arteriovenous malformations. Pediatr Neurosurg 45: 296-304, 2009.

19. Ahn JY, Kim OJ, Joo YJ and Joo JY: Dural arteriovenous malformation occurring after craniotomy for pial arteriovenous malformation. J Clin Neurosci 10: 134-136, 2003.

20. Watanabe A, Takahara Y, Ibuchi Y and Mizukami K: Two cases of dural arteriovenous malformation occurring after intracranial surgery. Neuroradiology 26: 375-380, 1984.

21. Ugrinovski J, Vrcakovski $M$ and Lozance K: Dural arteriovenous malformation secondary to meningioma removal. $\mathrm{Br} \mathrm{J}$ Neurosurg 3: 603-607, 1989.

22. Lewis AI, Rosenblatt SS and Tew JM Jr: Surgical management of deep-seated dural arteriovenous malformations. J Neurosurg 87: 198-206, 1997.

23. Martins C, Yasuda A, Campero A, Ulm AJ, Tanriover N and Rhoton A Jr: Microsurgical anatomy of the dural arteries. Neurosurgery 56 (2 Suppl): S211-S251, 2005.

24. Davidson AS and Morgan MK: The embryologic basis for the anatomy of the cerebral vasculature related to arteriovenous malformations. J Clin Neurosci 18: 464-469, 2011.

25. Kosnik EJ, Hunt WE and Miller CA: Dural arteriovenous malformations. J Neurosurg 40: 322-329, 1974.

26. Awad IA, Little JR, Akarawi WP and Ahl J: Intracranial dural arteriovenous malformations: Factors predisposing to an aggressive neurological course. J Neurosurg 72: 839-850, 1990.

27. Solomon RA and Connolly ES Jr: Arteriovenous malformations of the brain. N Engl J Med 376: 1859-1866, 2017.

28. Crimmins M, Gobin YP, Patsalides A and Knopman J: Therapeutic management of cerebral arteriovenous malformations: A review. Expert Rev Neurother 15: 1433-1444, 2015.

29. Lawton MT, Rutledge WC, Kim H, Stapf C, Whitehead KJ, Li DY, Krings T, terBrugge K, Kondziolka D, Morgan MK, et al: Brain arteriovenous malformations. Nat Rev Dis Primers 1: $15008,2015$. 
30. Ohata K, Takami T, El-Naggar A, Morino M, Nishio A, Inoue Y and Hakuba A: Posterior approach for cervical intramedullary arteriovenous malformation with diffuse-type nidus. Report of three cases. J Neurosurg 91 (Soppl 1): S105-S111, 1999.

31. Stein KP, Moenninghoff C, Kneist A, Sandalcioglu IE, Forsting M and Sure U: Transdural blood supply in cerebral arteriovenous malformations: A systematic evaluation of angioarchitecture. AJNR Am J Neuroradiol 39: 2307-2312, 2018.

32. Dahl RE and Kline DG: Intraparenchymal arteriovenous malformations with predominant external carotid artery contribution. J Neurosurg 41: 681-687, 1974.

33. Reul J, Thron A, Laborde G and Bruckmann H: Dural arteriovenous malformations at the base of the anterior cranial fossa: Report of nine cases. Neuroradiology 35: 388-393, 1993.

34. Lasjaunias $P$ and Berenstein A: Surgical neuroangiography. Vol 2: Endovascular treatment of craniofacial lesions. Berlin Springer-Verlag, 1987, pp 273-3.

35. Farhat HI: Cerebral arteriovenous malformations. Dis Mon 57: 625-637, 2011.

36. Jin H, Qiu H, Chen C, Ge H, Li Y and He H: Embolization of feeding arteries and symptom alleviation of mixed dural-pial arteriovenous malformations. Chin Neurosurg J 4: 5, 2018.

37. Vinuela F, Fox AJ, Pelz DM and Drake CG: Unusual clinical manifestations of dural arteriovenous malformations. J Neurosurg 64: 554-558, 1986.

38. Rengachary SS and Szymanski DC: Subdural hematomas of arterial origin. Neurosurgery 8: 166-172, 1981.

39. Kominato Y, Matsui K, Hata Y, Matsui K, Kuwayama N, Ishizawa $\mathrm{S}$ and Takizawa $\mathrm{H}$ : Acute subdural hematoma due to arteriovenous malformation primarily in dura mater: A case report. Leg Med (Tokyo) 6: 256-260, 2004

40. Kader A, Young WL, Pile-Spellman J, Mast H, Sciacca RR, Mohr JP and Stein BM: The influence of hemodynamic and anatomic factors on hemorrhage from cerebral arteriovenous malformations. Neurosurgery 34: 801-807; discussion 807-808, 1994.

41. Ding D, Starke RM, Quigg M, Yen CP, Przybylowski CJ, Dodson BK and Sheehan JP: Cerebral arteriovenous malformations and epilepsy, Part 1: Predictors of seizure presentation. World Neurosurg 84: 645-652, 2015.

42. Ding D, Quigg M, Starke RM, Yen CP, Przybylowski CJ Dodson BK and Sheehan JP: Cerebral arteriovenous malformations and epilepsy, Part 2: Predictors of seizure outcomes following radiosurgery. World Neurosurg 84: 653-662, 2015

43. Lamas E, Lobato RD, Esperarza J and Escudero L: Dural posterior fossa AVM producing raised sagittal simus pressure. Case report. J Neurosurg 46: 804-810, 1977.

44. Obrador S, Soto M and Silvela J: Clinical syndromes of arteriovenous malformations of the transverse-sigmoid sinus. J Neurol Neurosurg Psychiatry 38: 436-451, 1975.

45. Yamamoto M, Fukushima T, Sakamoto $S$, Hashimoto $T$ Tomonaga $\mathrm{M}$ and Goto $\mathrm{K}$ : Isolated trochlear nerve palsy caused by mixed dural-pial arteriovenous malformation of the anterior cranial fossa: A case report. No Shinkei Geka 21: 177-181, 1993 (In Japanese).

46. Ito M, Sonokawa T, Mishina H, Iizuka $\mathrm{Y}$ and Sato K: Dural arteriovenous malformation manifesting as tic douloureux. Surg Neurol 45: 370-375, 1996.

47. Yoshida S and Yamamoto T: Intracerebral arteriovenous malformation supplied by ethmoidal arteries-case report. Neurol Med Chir (Tokyo) 33: 166-169, 1993.

48. Lewis AI, Tomsick TA and Tew JM Jr: Management of tentorial dural arteriovenous malformations: Transarterial embolization combined with stereotactic radiation or surgery. J Neurosurg 81: 851-859, 1994.

49. Chandler HC Jr and Friedman WA: Successful radiosurgical treatment of a dural arteriovenous malformation: Case report. Neurosurgery 33: 139-141; discussion 141-132, 1993.
50. Halbach VV, Higashida RT, Hieshima GB, Rosenblum M and Cahan L: Treatment of dural arteriovenous malformations involving the superior sagittal sinus. AJNR Am J Neuroradiol 9: 337-343, 1988

51. Hidaka H, Terashima H, Tsukamoto $Y$, Nakata $H$ and Matsuoka S: Radiotherapy of dural arteriovenous malformation in the cavernous sinus. Radiat Med 7: 160-164, 1989.

52. Flynn TH, McSweeney S, O'Connor G, Kaar G and Ryder DQ: Dural AVM supplied by the ophthalmic artery. Br J Neurosurg 21: 414-416, 2007.

53. Houkin K, Sato M, Echizenya K and Nakagawa T: Mixed pial-dural arteriovenous malformation. Case report. No Shinkei Geka 12 (3 Suppl): S347-S352, 1984 (In Japanese).

54. Morgan MK, Davidson AS, Assaad NNA and Stoodley MA: Critical review of brain AVM surgery, surgical results and natural history in 2017. Acta Neurochir (Wien) 159: 1457-1478, 2017.

55. Gliemroth J, Nowak G and Arnold H: Dural arteriovenous malformation in the anterior cranial fossa. Clin Neurol Neurosurg 101: 37-43, 1999.

56. Shima T, Yamane K, Nishida M, Hatayama T and Yamanaka C Successful surgical treatment of a large mixed pial-dural arteriovenous malformation. J Clin Neurosci 1 (Suppl 7): S30-S32, 2000.

57. Reul J: Neuro-interventional treatment of cerebrovascular malformations. Aktuelle Radiol 8: 47-57, 1998 (In German).

58. Borota L, Mahmoud E, Nyberg C, Lewen A, Enblad P and Ronne-Engstrom E: Dual lumen balloon catheter-An effective substitute for two single lumen catheters in treatment of vascular targets with challenging anatomy. J Clin Neurosci 51: 91-99, 2018.

59. Paramasivam S, Niimi Y, Fifi J and Berenstein A: Onyx embolization using dual-lumen balloon catheter: Initial experience and technical note. J Neuroradiol 40: 294-302, 2013.

60. Samson DS and Welch BG: Editorial: Arteriovenous malformation and embolization. J Neurosurg 118: 967-968; discussion 968 2013.

61. Zipfel GJ: Editorial: Arteriovenous malformations and embolization. J Neurosurg 122: 1490-1491, 2015.

62. Shi L, Li W, Xu K, Guo YB and Yu JL: Current status of combined surgical and endovascular methods for intracranial neurovascular diseases in a hybrid operating room. Int J Clin Exp Med 9: 20741-20753, 2016.

63. Yu JL, Guo YB, Xu BF, Chen X and Xu K: Onyx embolization and surgical removal as a treatment for hemorrhagic AVM in a hybrid operating room. Int J Clin Exp Med 9: 22494-22501, 2016

64. Ratliff J and Voorhies RM: Arteriovenous fistula with associated aneurysms coexisting with dural arteriovenous malformation of the anterior inferior falx. Case report and review of the literature. J Neurosurg 91: 303-307, 1999.

65. Maki Y, Funaki T, Takahashi JC, Takagi Y, Ishii A, Kikuchi T, Yoshida K, Makino Y and Miyamoto S: 'True' mixed pial-dural arteriovenous malformation: A case report. No Shinkei Geka 42: 745-750, 2014 (In Japanese).

This work is licensed under a Creative Commons Attribution-NonCommercial-NoDerivatives 4.0 International (CC BY-NC-ND 4.0) License. 